\title{
Educação, Promoção e Prevenção de Saúde Bucal: uma investigação de diferentes métodos de aprendizagem em escolares de 8 a 11 anos.
}

\author{
Lenise Maria Coral ${ }^{\star}$, Dagmar de Paula Queluz.
}

\section{Resumo}

O objetivo deste estudo foi investigar os diferentes métodos de aprendizagem acerca da saúde oral. A amostra selecionada foram escolares do terceiro ao quinto ano, dos anos iniciais do Ensino fundamental de uma escola pública de Piracicaba, na faixa etária de 8 a 11 anos. Na coleta de dados foi utilizado antes e após a aplicação de uma metodologia distinta em sete grupos (cada grupo 20 escolares); um questionário sobre saúde oral, dividido em duas partes: a primeira com questões acerca de conhecimentos básicos de saúde oral, e a segunda com conhecimentos específicos sobre saúde oral. As metodologias de aprendizagem distinta foram: palestra com uso de Flip-chart e Macromodelo, teatro, dinâmica de montagem de cartazes, palestras com uso de Datashow/Slide e vídeo, literatura ilustrada, panfletos, roda de conversa. Todos os grupos apresentaram aumento da média percentual de acertos, sendo que Palestra com uso de Flip-chart e Macro-modelos apresentou 24\%, Teatro, 22\%, Montagem de cartazes, 15\%, DataShow, Slide e Vídeo, 22\%, Literatura Ilustrada, 23\%, Panfleto 15\% e Roda de Conversa 16\%. Todos os métodos apresentaram resultados eficazes, variando a predominancia de acertos conforme as perguntas analisadas. $\mathrm{O}$ método "Data-show, Slide e Vídeo" perante análise apresentou com maior frequência os melhores resultados.

\section{Palavras-chave:}

Saúde Bucal, Escolares, Aprendizagem.

\section{Introdução}

A promoção é definida como medidas, planos e políticas de saúde pública que trazem a autonomia do indivíduo com os cuidados de saúde, trazendo o incentivo a medidas que tragam melhores condições de vida, enquanto que a prevenção se trata de uma ação antecipada, que busca cessar a continuidade futura de uma doença (Czeresnia, 2003). Ao se tratar de diferentes métodos de aprendizagem (Faria, 2008; Braga e Medina, 2010; Castilho et al, 2013) como palestras educativas com abordagens para a área de saúde geral, é observado que estudantes se sentem atraídos por temas que discutem a realidade em que estão inseridos. Destaca-se que além das palestras voltadas para a educação em saúde ampliarem o conhecimento e senso crítico de determinado grupo social, ela modifica a consciência,prevalecendo a ação relacionada ao tema apresentado (Fujimori et al, 2008).

Considerando a importância da aprendizagem se tornar agradável, atraente, estimulante e enriquecedora, e que os escolares de 8 a 11 anos compreendam de forma simples; o objetivo deste estudo foi investigar os diferentes métodos de aprendizagem acerca da saúde oral, compondo a amostra escolares do terceiro ao quinto ano, dos anos iniciais do Ensino fundamental de uma escola pública de Piracicaba.

\section{Resultados e Discussão}

O estudo foi aprovado pelo Comitê de Ética em Pesquisa da Faculdade de Odontologia de Piracicaba UNICAMP, pelo CAAE: 97322718.0.0000.5418.

A amostra selecionada foram escolares do terceiro ao quinto ano, dos anos iniciais do Ensino fundamental de uma escola pública de Piracicaba, na faixa etária de 8 a 11 anos.

$\mathrm{Na}$ coleta de dados foi utilizado antes e após a aplicação de uma metodologia distinta em sete grupos (cada grupo 20 escolares); um questionário sobre saúde oral, dividido em duas partes: a primeira com questões acerca de conhecimentos básicos de saúde oral, e a segunda com conhecimentos específicos sobre saúde oral. As metodologias de aprendizagem distintas foram: palestra com uso de Flip-chart e Macro-modelo, teatro, dinâmica de montagem de cartazes, palestras com uso de Datashow/Slide e vídeo, literatura ilustrada, panfletos, roda de conversa.

Todos os grupos apresentaram aumento da média percentual de acertos, sendo que Palestra com uso de Flip-chart e Macro-modelos apresentou 24\%, Teatro, $22 \%$, Montagem de cartazes, 15\%, Data-Show, Slide e Vídeo, 22\%, Literatura llustrada, 23\%, Panfleto 15\% e Roda de Conversa 16\%. O método "Data-show, Slide e Vídeo" perante análise apresentou com maior frequência os melhores resultados. Assim como proposto por Oliveira e Costa (2018), A utilização de vídeos implicou no acesso a tecnologias, o uso desse método - que obteve os melhores resultados - pode ressaltar vários tópicos de forma sucinta e concisamente, que além de estimular a aprendizagem em pontos específicos, auxilia na formação de novos conhecimentos e na concepção de uma nova percepção. O método literatura ilustrada revelou-se como eficiente, e conforme afirma Faria (2008), a ilustração fez parte descritiva do texto, demonstrando aspectos físicos estáticos da cena em questão ou ações, que se descritas levariam o texto ser considerado não atrativo. Esse método de aprendizagem apresentou destaque, pois reuniu várias informações em um pequeno espaço.

\section{Conclusões}

O estudo permiti concluir que o conhecimento prévio varia conforme os grupos, sendo brevemente mais elevado nos grupos de idades superiores. O método "Data-show, Slide e Vídeo" perante análise apresentou com maior frequência os melhores resultados.

Agradecimentos

À UNICAMP, PRP, Financiada pelo SAE/Unicamp. 